\title{
Leaf transpiration of drought tolerant plant can be captured by hyperspectral reflectance using PLSR analysis
}

Quan Wang ${ }^{(1)}$, Jia Jin ${ }^{(2-3)}$

\section{Introduction}

Plant transpiration, defined as the process of water movement through a plant and its evaporation from aerial parts, is a basic process regulated over short time periods by stomatal conductance $\left(g_{s}-M c-\right.$ Dowell et al. 2008) and is a key parameter in climate models for quantifying the biosphere-atmosphere interactions (Naithani et al. 2012). So far, this process has not been fully understood yet, especially in arid areas, where water resources are one of the major constraints. In this context, a more accurate understanding of plant transpiration is very important for water cycle and climate modeling (Hunsmann et al. 2008), especially for arid environments where water plays a determinant role in the ecosystem functions.

Field measurements of leaf scale transpi-

\begin{abstract}
A clear understanding of plant transpiration is a crucial step for water cycle and climate modeling, especially for arid ecosystems in which water is one of the major constraints. Traditional field measurements of leaf scale transpiration are always time-consuming and often unfeasible in the context of large spatial and temporal scales. This study focused on a dominant native plant in the arid land of central Asia, Haloxylon ammondendron, with the aim of deriving the leaf-scale transpiration through hyperspectral reflectance using Partial Least Squares Regression (PLSR) analysis. The results revealed that the PLSR model based on the first-order derivative spectra at wavelengths selected through stepwise regression analysis can closely trace leaf transpiration with a high accuracy $\left(R^{2}=0.78\right.$, RMSE $\left.=1.62 \mu \mathrm{mol} \mathrm{g}^{-1} \mathrm{~s}^{-1}\right)$. The accuracy is also relatively stable even at a spectral resolution of $10 \mathrm{~nm}$, which is very close to the bandwidths of several running satellite-borne hyperspectral sensors such as Hyperion. The results also proved that the first-order derivative spectra within the shortwave infrared (SWIR) domain, especially at 2435, 2440, 2445, and $2470 \mathrm{~nm}$, were critical for PLSR models to predict leaf transpiration. These findings highlight a promising strategy for developing remote sensing methods to potentially characterize transpiration at broad scales.
\end{abstract}

Keywords: Arid Land, Leaf Transpiration, PLSR, Derivative Spectra, Droughttolerant, Haloxylon ammondendron

ration are always based on the measurement of vapor added by transpiration into the air inside a chamber enclosing the leaf or a leaf surface (Jarvis \& Catsky 1971, Pearcy et al. 1989). Such methods are time-consuming and often unfeasible for tracing the dynamics of transpiration. To tackle this problem, various models considering the energy balance have been developed for simulating the multi-scale transpiration, e.g., the model at the level of individual leaves (Dauzat et al. 2001, Smith \& Geller 1980), the multilayer model for estimating daily transpiration of the whole plant (Ansley et al. 1991, Raupach \& Finnigan 1988), and the Penman-Monteith's model for canopy transpiration or regional level evaporation (He et al. 2013, Monteith 1965, Zheng \& Wang 2014). However, modelling the transpiration of a plant or a stand in a
(1) Graduate School of Agriculture, Shizuoka University, Shizuoka $422-8529$ (Japan); (2) Xinjiang Institute of Ecology and Geography, CAS, Urumqi 830011 (China); (3) University of Chinese Academy of Sciences, Beijing 100049 (China)

@ Quan Wang (wang.quan@shizuoka.ac.jp)

Received: Mar 05, 2015 - Accepted: Aug 06, 2015

Citation: Wang Q, Jin J (2015). Leaf transpiration of drought tolerant plant can be captured by hyperspectral reflectance using PLSR analysis. iForest 9: 30-37. - doi: 10.3832/ifor1634008 [online 2015-10-05]

Communicated by: Davide Travaglini given environment is challenging due to the interaction of complex physical and physiological phenomena (Dauzat et al. 2001), which led to argue about the performances of these models.

Such challenge calls for the development of new approaches to determine absolute transpiration rates of plant leaves. Recently, the transpiration rate sensor with a multi-channel hygrometer using near infrared (NIR) tunable diode laser absorption spectroscopy (TDLAS) at $1.37 \mu \mathrm{m}$ was developed (Hunsmann et al. 2008). This new tool can be used in the measure of the absolute, high-resolution water transpiration. However, a straightforward relationship between leaf transpiration and reflected information has still to be verified, while it has already been done for other parameters related to the biological status of plants (Dorigo et al. 2007).

With the development of hyperspectral remote sensing and imaging spectrometry, many empirical approaches have been proposed for spectroscopic analysis, such as vegetation indexes, single regression, stepwise multiple linear regression, partial least squares regression (PLSR), artificial neural networks, and others (Dorigo et al. 2007). PLSR, a multivariate extension of the multiple regression model, is the most widely used approach in chemometrics, owing to its ability to analyze data with many noisy, collinear, and even incomplete variables in both input $(\mathrm{X})$ and output $(\mathrm{Y})$ measurements (Wold et al. 2001). It has been 
claimed that PLSR analysis can provide a more useful and accurate estimation tool for plant spectroscopic analysis compared with other empirical approaches; for example, PLSR can improve the prediction of green biomass and leaf nitrogen concentration compared to hyperspectral indices (Cho et al. 2007, Hansen \& Schjoerring 2003), and carotenoid estimation results based on PLSR were significantly better than those based on stepwise multiple linear regression and vegetation indexes ( $\mathrm{Yi}$ et al. 2014). In addition, the PLSR model is more suitable than the multiple linear regression model for predicting the nitrogen content at the heading stage using the hyperspectral reflectance (Ryu et al. 2011).

Reflected data collected by spectrometers hold thousands of generally collated bands within the visible to near-infrared domains. PLSR deals efficiently with such data sets including many highly correlated bands by avoiding the potential overfitting typically associated with multiple linear regression (Huang et al. 2004). Many studies have applied PLSR to estimate various biochemical and nutritional parameters of leaves and canopies through hyperspectral reflectance data, for example biomass estimation (Cho et al. 2007, Fu et al. 2014, Hansen \& Schjoerring 2003), nitrogen concentration/content prediction (Hansen \& Schjoerring 2003, Huang et al. 2004, Inoue et al. 2012, Nguyen \& Lee 2006, Ryu et al. 2009, 2011), phosphorous concentration and potassium content determination (Ramoelo et al. 2013, Zhang et al. 2013), glucose, sucrose, specific gravity, and soluble solids prediction (Rady et al. 2014) and carotenoids estimation ( $\mathrm{Yi}$ et al. 2014). In comparison, far fewer attempts have targeted the determination of physiological functional attributes from reflectance using PLSR analysis. Among the few attempts carried out, Serbin et al. (2012) reported that the key determinants of photosynthetic capacity, namely the maximum rates of RuBP carboxylation $\left(V_{\text {cmax }}\right)$ and regeneration $\left(J_{\max }\right)$, can be effectively captured by reflectance using PLSR models even across species (Serbin et al. 2012). However, to the best of our knowledge, yet there is no such study on transpiration.

On the other hand, former studies exploring plant traits from reflectance suggested that a number of other modes or transformed formats of spectra, such as transmittance and derivative spectra, were helpful for data mining (Rady et al. 2014). Among those, derivative techniques are commonly used and, in particular, the firstorder derivative transformation is widely employed in hyperspectral data analysis (Abdel-Rahman et al. 2014). Previous studies on the relationship between canopy transpiration and hyperspectral indexes also proved that the first-order derivative transformation is superior to the original reflectance for tracing the dynamics of canopy transpiration (Jia \& Wang, unpublished). Hence, the combination of deriva- tive techniques and the PLSR model for tracing leaf-scale transpiration is also worthy to be explored.

The main objective of the present study is to examine data taken simultaneously on both leaf transpiration and reflected spectra, from which the PLSR model was built up, to estimate leaf transpiration based on hyperspectral reflectance. The final target was the development of a methodology that can trace leaf transpiration promptly and accurately. This study focused on a dominant native plant in deserts, Haloxylon ammondendron, a well-distributed species in the arid land of northwestern China as well as in central Asia. Detailed goals were: (1) to verify the statistical relationships between transpiration and spectra; (2) to select corresponding feature bands that can be used for building up a PLSR model to estimate transpiration; and (3) to build a PLSR model based on selected feature bands that can be used in tracing leaf-scale transpiration.

\section{Materials and methods}

\section{Study site}

Field measurement was carried out in 2013 at the Integrated Remote Sensing Experimental Site, $20 \mathrm{~km}$ north of the Fukang Station of Desert Ecology, Xinjiang Institute of Ecology and Geography, Chinese Academy of Sciences, located at $44^{\circ} 17^{\prime} \mathrm{N}$, $87^{\circ} 56^{\prime} \mathrm{E}$, with an elevation of $475 \mathrm{~m}$ a.s.l.

This region has a continental arid temperate climate and drought is quite prevalent. The extreme minimum temperature can reach $-40{ }^{\circ} \mathrm{C}$ in winter, while the maximum temperature can be $40^{\circ} \mathrm{C}$ in summer in the growing season. It is so far from the sea that the annual mean precipitation is as low as $80-160 \mathrm{~mm}$, while pan evaporation can reach about $2000 \mathrm{~mm}$ in summer due to the high temperature ( $\mathrm{Li} \&$ Wang 2012). As a result, the drought-resistant plant $H$. ammodendron, a stem-succulent shrub and typical desert plant, is the dominant species in this area and the focus of this research. H. ammodendron possesses distinct structural features of xeromorphism, in which the leaves are reduced in size and degenerated or exist as basal leaves ( $\mathrm{Li} \&$ Li 1981).

\section{Field measurements}

\section{Leaf-scale transpiration}

The leaf-scale transpiration rate (Tr) was measured using a portable gas exchange system (HCM-1000, Walz, Germany). Diurnal variation measurements were made once per month at the key growth stages in the growing season from June to August. In each diurnal course measurement, two groups of leaves from the upper and lower layers of the sampling canopy were selected and inserted into the leaf chamber of the HCM-1000 for leaf transpiration measurement once per hour from 8:00 to 18:00 local time. As the system measures the change of $\mathrm{H}_{2} \mathrm{O}$ pressure, and the transpiration rate $\left(\mathrm{Tr}, \mu \mathrm{mol} \mathrm{g} \mathrm{s}^{-1}\right)$ is calculated from the pre-set weight, the leaves placed in the chamber were clipped for fresh weight measurement. The real transpiration rate values were then converted from the values recorded by the HCM-1000.

\section{Leaf reflectance and derivative spectra}

Leaf hyperspectral spectra data (350 to $2500 \mathrm{~nm}, 1 \mathrm{~nm}$ step) were recorded with a field spectroradiometer (ASD FR Inc., Boulder, CO, USA) equipped with a leaf clip which can illuminate the leaves with a constant inner light source. To obtain spectra, five measurements were taken each time and the average value was used for further analysis. As the transpiration measurements took about 10 minutes each, the leaf spectra measurement was conducted on the leaves next to those whose transpiration was being measured in the meantime.

Based on the original reflectance data, the first-order derivative spectra of leaf reflectance were calculated using the following formula (eqn. 1):

$$
d_{\lambda}=\left(\frac{d R}{d \lambda}\right)=\frac{R_{\lambda+1}-R_{\lambda}}{\Delta \lambda}
$$

where $d_{\lambda}$ is the first-order derivative of reflectance at the wavelength of band $\lambda$, $R_{\lambda+1}$ and $R_{\lambda}$ are the reflectance at the wavelengths $\lambda$ and $\lambda+1$ respectively, and $\Delta \lambda$ is the wavelength increment of the spectrometer.

\section{Modeling approaches}

\section{Band selection}

Selection of wavelengths is critical for the predictive ability of the PLSR model (Osborne et al. 1997). Using the original $1 \mathrm{~nm}$ step, the spectrum had massively redundant information. To decrease the computation time required for variable and component selection (Serbin et al. 2012), the entire spectrum from 350 to $2500 \mathrm{~nm}$ was sub-sampled by retaining every fifth band of the total wavelengths (almost equal to a $5 \mathrm{~nm}$ resolution). Relevant spectral wavelengths for PLSR models were then selected based on a stepwise approach. Stepwise regression is a systematic method of adding and removing terms from a multilinear model based on their statistical significance in the regression. At each step, the $p$ value of an F-statistic is computed to test the model with and without a potential term/variable (Jennrich 1977). When the term is not included in the model, the null hypothesis is that the term would have a zero coefficient when it is added to the model. If there is sufficient evidence to reject the null hypothesis, the term is included in the model. Conversely, if a term is currently included in the model, the null hypothesis is that the term has a zero coefficient. If there is insufficient evidence to reject the null hypothesis, the term is removed from the model. 


\section{Cross-validation}

With numerous X-variables, there is a substantial risk of "over-fitting" in any empirical modeling procedure. To this purpose, it is necessary to test the predictive significance of each PLSR uncorrelated principal components (PCs) generated from selected spectral wavelengths, and to stop when components start to be non-significant (Wold et al. 2001).

Cross-validation is a model validation technique for assessing how the results of a statistical analysis will generalize to an independent data set. Cross-validation was used to determine the number of principal components of the PLSR models by minimizing the predicted residual sums of squares (PRESS - Chen et al. 2004). The "leave-p-out cross-validation" (LPO CV) approach, which implies the use of $p$ observations for the validation set and the rest as the training set (Shao 1993), was applied in this study. Seven (15\%) out of 45 samples were used for validation, while the remaining 38 samples were included in the training set.

\section{Partial least squares analysis}

To calculate the spectral loadings (or regression coefficients) of bands, a standard PLSR approach was applied, using the relevant spectral wavelengths selected by the stepwise regression, and the number of components determined by cross-validation. PLSR is a basically linear way to estimate relevant parameters in a model by reducing the large number of measured collinear spectral variables to a few uncorrelated principal components (PCs), which represent the relevant structural information contained in the measures of reflectance (Hansen \& Schjoerring 2003). More details about the PLSR technique can be found in Wold et al. (2001).

The coefficient of determination $\left(R^{2}\right)$ and the root mean square error (RMSE) between measured and estimated transpiration values were then calculated and used to quantify the performance of the PLSR model. Of course, an effective model for assessing the transpiration should have a high $\mathrm{R}^{2}$ and small RMSE.

\section{Results}

\section{Transpiration, reflectance, and their correlations}

Diurnal variation in leaf transpiration was evident throughout the daytime, with a double-peak trend. Leaf transpiration rate rises in the morning, reaches the first peak around 11:00 local time, and then drops to low levels until about 17:00, due to the high temperature and the intensive light. Later, the transpiration rate rises again reaching a second peak, and then drops to the trough as the temperature falls, at the end of the daytime. Based on our field measurements taken from June to August, seasonal changes in leaf transpiration rate were not fully evident, but transpiration rates appeared

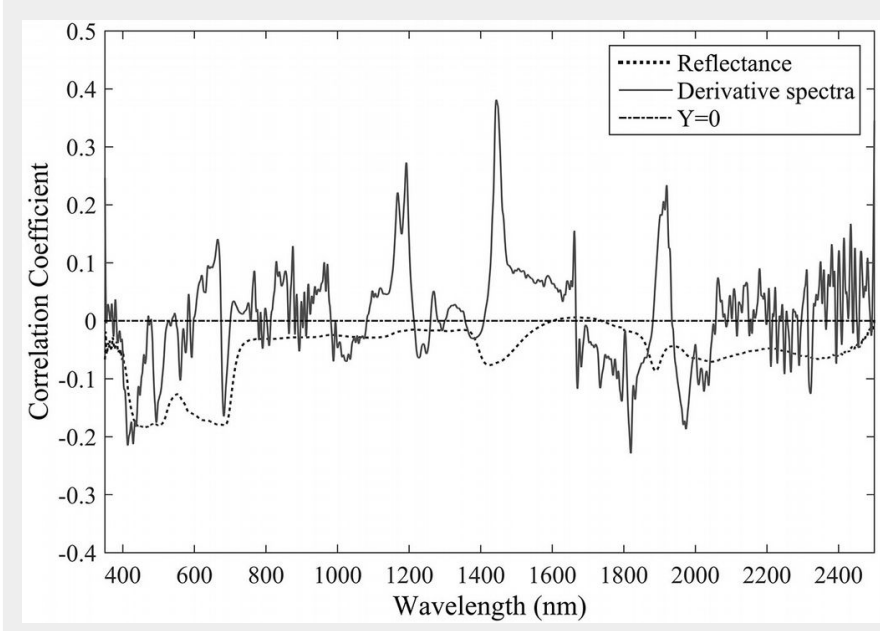

Fig. 1 - Correlation between reflectance/first-order derivative spectra and leaf transpiration.

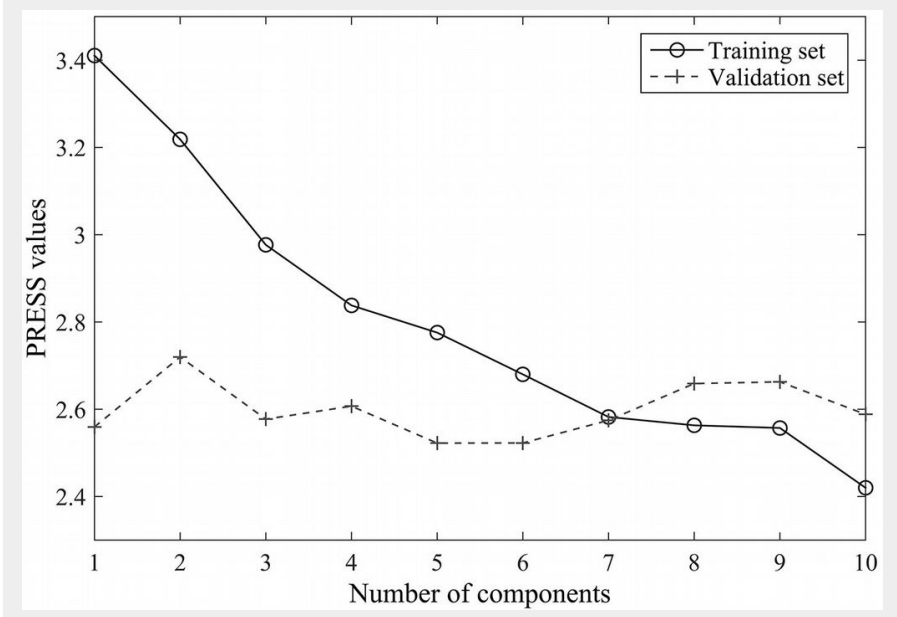

Fig. 2 - Cross-validation results for the original reflectance data set: relationships between the numbers of components and the predicted residual sums of squares (PRESS).

to be higher in June than in July/August.

To generate the PLSR model for the estimation of leaf transpiration, both original reflectance and the first-order derivative spectra were examined. Generally, the leaves have the highest reflectance in August, though this trend was partially confounded by the diurnal variation in reflectance. Although monotonic variations in the reflectance and in the first-order derivative spectra cannot be identified over the whole range (350-2500 nm), consistent changes at some particular wavelengths were detected based on their high correlation coefficients with the transpiration rate.

The first-order derivative spectra clearly captured leaf transpiration more effectively, with higher correlation coefficients at many featured wavelengths (Fig. 1). In general, negative (though non-significant) correlations between the original reflectance wavelengths and leaf transpiration were identified throughout the range 350-

Tab. 1 - The coefficients of the ten wavelengths from the original reflectance data set that were included in the PLSR model. (Int): intercept.

\begin{tabular}{ccccccccccc}
\hline \multirow{2}{*}{ Int } & \multicolumn{8}{c}{ Wavelength $(\mathrm{nm})$} \\
\cline { 2 - 11 } & $\mathbf{3 7 0}$ & $\mathbf{3 7 5}$ & $\mathbf{4 4 0}$ & $\mathbf{4 6 5}$ & $\mathbf{1 4 0 0}$ & $\mathbf{1 5 4 5}$ & $\mathbf{1 7 9 5}$ & $\mathbf{1 8 0 0}$ & $\mathbf{1 8 6 0}$ & $\mathbf{1 8 8 5}$ \\
\hline 2.96 & -488.15 & 900.42 & -716.20 & 216.04 & -750.42 & 1672.63 & -395.58 & -623.18 & 465.25 & -297.06 \\
\hline
\end{tabular}

$2500 \mathrm{~nm}$, with the highest correlation coefficient at the wavelength of $463 \mathrm{~nm}$. Contrastingly, using the first-order derivative spectra several significant correlations with leaf transpiration were identified around the wavelengths 1190, 1470, and $1910 \mathrm{~nm}$, across the NIR (near-infrared) and SWIR (short-wave infrared) regions.

\section{PLSR model based on original reflectance}

Stepwise regression analysis based on the original reflectance data and transpiration rate was carried out first. Ten different wavelengths $(465,1545,375,1860,440$, $1400,1800,1795,370$, and $1885 \mathrm{~nm}$ ) were finally selected for the PLSR analysis based on the results of the stepwise regression analysis.

The results of the cross-validation carried out to determine the number of components for PLSR analysis are reported in Fig. 2. The predicted residual sums of squares 
Fig. 3 - The observed versus estimated leaf transpiration values from the PLSR model based on the original reflectance data.

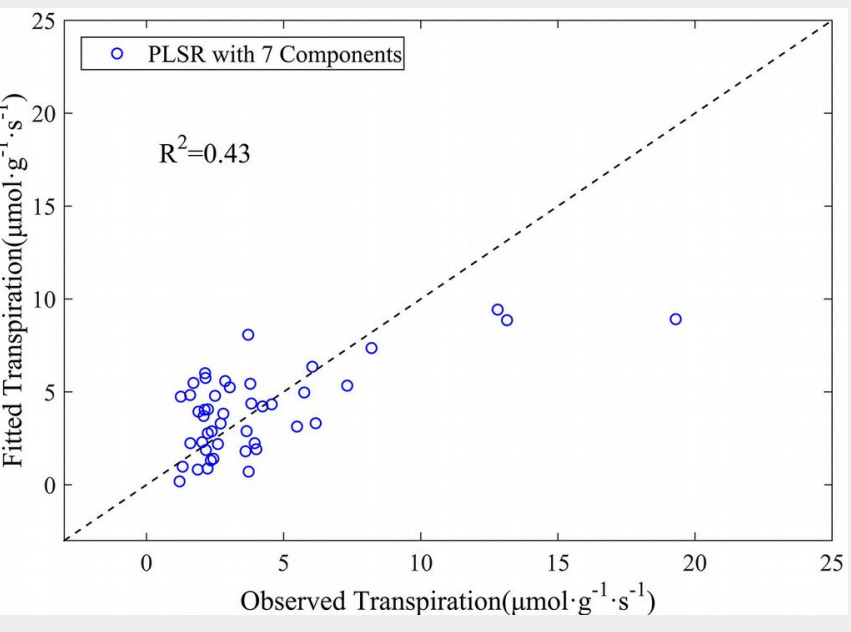

Fig. 4 - Cross-validation results for first-order derivative spectra mode: the relationships between the numbers of components and the predicted residual sums of squares (PRESS).

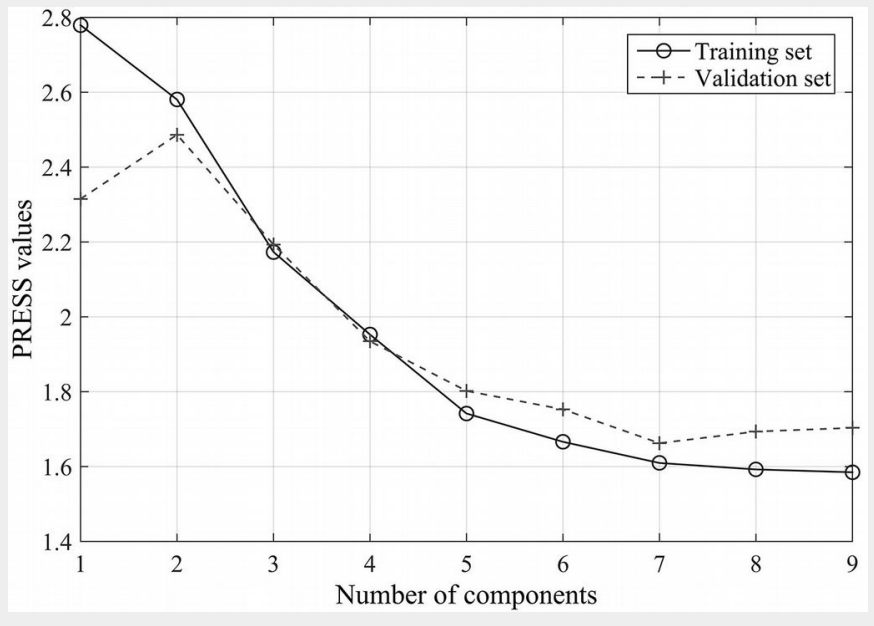

Fig. 5 - The observed versus estimated leaf transpiration values from the PLSR model based on

the first-order derivative spectra.

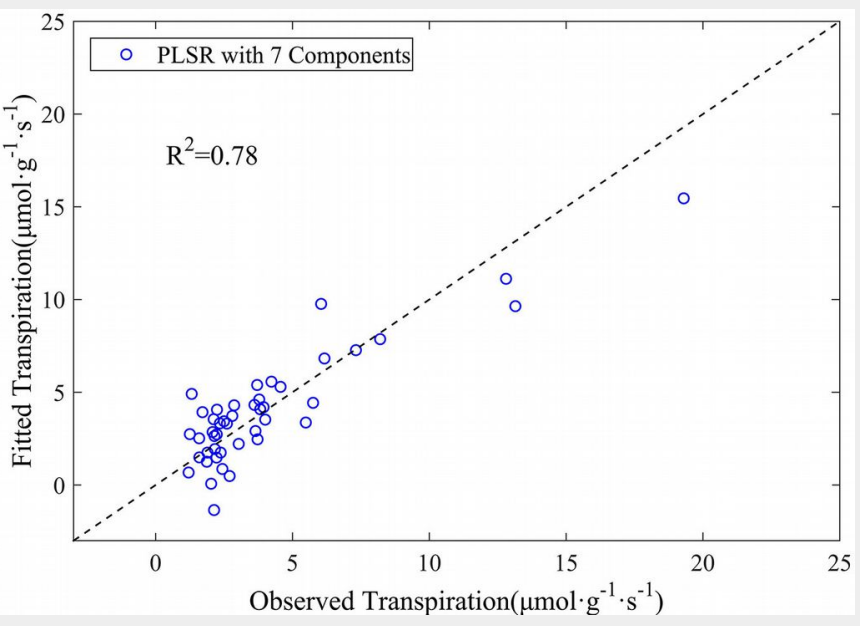

(PRESS) of the training set decreases monotonically with the number of components, while the values of the validation set initially decrease and then increase later. The predictive ability of the PLSR components started to be non-significant after the $8^{\text {th }}$ PLSR component was added to the model, thus seven components were selected to develop the PLSR model in the following analysis.

Tab. 1 lists the coefficients of the 10 wavelengths finally included in the PLSR model using the original reflectance data. The relationship between the observed leaf transpiration and its estimate obtained by the PLSR model is shown in Fig. 3. The results reveal that the PLSR model based on original reflectance measures does not perform very well in estimating leaf transpiration, although the above relationship was statistically significant. The coefficient of determination $\left(R^{2}\right)$ for transpiration estimation was 0.43 , with an RMSE of $2.6 \mu \mathrm{mol}$ $\mathrm{g}^{-1} \mathrm{~s}^{-1}(p<0.001)$. Despite leaf transpiration could be captured by reflectance measures to some extent, the PLSR model based on the original reflectance data yielded only fairly good results.

\section{PLSR model based on derivative spectra}

Stepwise regression analysis, cross-validation, and PLSR analysis were carried out as described above on the first-order derivative spectra of leaf reflectance, obtaining much better performances in model predictions (Fig. 4).

Unlike the original spectra data, wavelengths of the first-order derivative spectra selected by stepwise regression analysis (9) were mainly distributed within the SWIR domain, and were namely 2435,2355 , 1190, 2180, 2445, 2470, 2275, 2440, and 675 nm. Cross-validation results showed that the optimal number of components for the PLSR analysis was seven. The PRESS values obtained for the training set and the validation set were 1.61 and 1.66 , respectively.

The PLSR model was finally run based on the above nine wavelengths of the firstorder derivative spectra of leaf reflectance. Their coefficients obtained from the model are listed in Tab. 2. The coefficient of determination $\left(R^{2}\right)$ for the transpiration estimate reached 0.78 , and the RMSE between the observed and predicted values was 1.62 $\mu \mathrm{mol} \mathrm{g} \mathrm{g}^{-1}$ (Fig. 5), clearly indicating the superiority of the use of first-order derivative spectra for the prediction of leaf transpiration rate. We concluded that the PLSR model could predict leaf transpiration with higher accuracy when first-order derivative spectra were used, as compared with the original reflectance data.

\section{Discussion}

Important wavebands identified for leaf transpiration estimation

In the scientific literature, reflectance has rarely been related to plant ecophysiological variables as compared with plant biochemical parameters, whose relationships with reflected wavelengths have been widely analyzed (Chappelle et al. 1992, Peñuelas \& Filella 1998). Indeed, only a few stu-

Tab. 2 - The coefficients of the nine selected wavelengths of the first-order derivative spectra included in the PLSR model.

\begin{tabular}{cccccccccc}
\hline \multirow{2}{*}{ Intercept } & \multicolumn{7}{c}{ Wavelength $(\mathrm{nm})$} \\
\cline { 2 - 10 } & $\mathbf{6 7 5}$ & $\mathbf{1 1 9 0}$ & $\mathbf{2 1 8 0}$ & $\mathbf{2 2 7 5}$ & $\mathbf{2 3 5 5}$ & $\mathbf{2 4 3 5}$ & $\mathbf{2 4 4 0}$ & $\mathbf{2 4 4 5}$ & $\mathbf{2 4 7 0}$ \\
\hline 3.06 & 23001.37 & 87810.41 & 23790.46 & -50988.63 & -51988.05 & 20650.22 & 18325.10 & 16480.77 & 7987.47 \\
\hline
\end{tabular}


dies have attempted to relate plant physiological parameters with hyperspectral reflected properties so far. Recent reports suggested that full-spectrum optical properties can potentially be used for assessing photosynthetic parameters such as $J_{\max }$ and $V_{\text {cmax }}$ (Doughty et al. 2011, Serbin et al. 2012). The only study in the literature focusing on the assessment of the whole tree transpiration using canopy spectral reflectance indexes also showed that the water index $\left(\mathrm{WI}-R_{900} / R_{970}\right)$ is well correlated with the whole plant transpiration $\left(R^{2}=\right.$ 0.668 - Marino et al. 2014).

In this study, the observed high collinearity throughout the full spectrum and poor knowledge of the feature wavelengths for transpiration led to the difficult task of selecting the relevant information to be included in the PLSR model. Stepwise regression analysis was performed to select the wavelengths to be considered in themodel, instead of using the entire spectrum (350-2500 nm). Tab. 3 shows the number of wavebands of the first-order derivative spectra as well as the original reflectance selected within the visible (VIS), NIR, shortwave infrared 1 (SWIR1), and shortwave infrared 2 (SWIR2) spectral regions.

To assess the reliability of the band-selection approach described above, we checked the performance of PLSR analysis using the entire spectrum $(350-2500 \mathrm{~nm})$ of first-order derivative data rather than the selected bands only. The generated PLSR model showed poor predictive performances in the estimation of leaf transpiration $\left(R^{2}=0.21\right.$, RMSE $\left.=3.07 \mu \mathrm{mol} \mathrm{g}{ }^{-1} \mathrm{~s}^{-1}\right)$. The low effectiveness of this model is reasonably due to large noise derived from the inclusion in the model of a large amount of irrelevant information from the full spectrum.

High linear correlations between leaf transpiration and the original reflectance were frequently noted within the wavelengths of $400-800 \mathrm{~nm}$ and around 1400 or $1900 \mathrm{~nm}$ (Fig. 1). The wavebands selected by stepwise regression analysis for PLSR modeling were also distributed in the VIS (350-700 nm) and SWIR1 (1300-1900 nm) regions, with four and six wavebands, respectively (Tab. 3 ). The lower performance of the PLSR model based on the original reflectance is likely due to the fact that the selected wavelengths are mainly related with other leaf parameters rather than transpiration or $g_{s}$. Indeed, wavebands such as 430-445 nm are known to be related to carotenoids, bands $531-570 \mathrm{~nm}$ to xanthophylls, and 550-680 $\mathrm{nm}$ and the "red-edge" position to chlorophyll (Peñuelas \& Filella 1998), which are not directly related to the water cycle.

More accurate predictions of leaf transpiration were obtained when first-order derivative spectra of the leaf reflectance were included in the PLSR model. Tab. 3 shows that most of the wavebands selected (seven out nine) were within the domain of
Tab. 3 - The number of wavebands selected for transpiration estimation PLSR modeling within the visible (VIS), near-infrared (NIR), short-wave 1 (SWIR1), and short-wave 2 (SWIR2) spectral regions.

\begin{tabular}{|c|c|c|c|c|c|c|}
\hline \multirow[b]{2}{*}{ Origin } & \multirow[b]{2}{*}{$\begin{array}{c}\text { PLSR } \\
\text { components }\end{array}$} & \multicolumn{5}{|c|}{ Number of wavebands } \\
\hline & & $\begin{array}{c}350-2500 \\
\mathrm{~nm}\end{array}$ & $\begin{array}{c}\text { VIS } \\
(350- \\
700 \mathrm{~nm})\end{array}$ & $\begin{array}{c}\text { NIR } \\
(700- \\
1300 \mathrm{~nm})\end{array}$ & $\begin{array}{c}\text { SWIR1 } \\
(1300- \\
1900 \mathrm{~nm})\end{array}$ & $\begin{array}{c}\text { SWIR2 } \\
(1900- \\
2500 \mathrm{~nm})\end{array}$ \\
\hline $\begin{array}{l}\text { Original } \\
\text { reflectance }\end{array}$ & 7 & 10 & 4 & 0 & 6 & 0 \\
\hline $\begin{array}{l}\text { Derivative } \\
\text { spectra }\end{array}$ & 7 & 9 & 1 & 1 & 0 & 7 \\
\hline
\end{tabular}

Tab. 4 - Loading weights $\left(L W, \times 10^{-4}\right)$ of each waveband for the PLSR model based on the first-order derivative spectra of reflectance for the estimation of leaf transpiration. (a): high absolute numerical values indicate a high loading weight of the waveband to the given principal component (PC).

\begin{tabular}{lrrrrrrrrr}
\hline \multirow{2}{*}{ Axis } & \multicolumn{10}{c}{ Wavelength $(\mathbf{n m})$} \\
\cline { 2 - 10 } & $\mathbf{6 7 5}$ & $\mathbf{1 1 9 0}$ & $\mathbf{2 1 8 0}$ & $\mathbf{2 2 7 5}$ & $\mathbf{2 3 5 5}$ & $\mathbf{2 4 3 5}$ & $\mathbf{2 4 4 0}$ & $\mathbf{2 4 4 5}$ & $\mathbf{2 4 7 0}$ \\
\hline PC1 & -0.28 & 0.51 & -0.41 & 0.59 & 0.38 & $3.68^{\mathrm{a}}$ & -0.20 & $3.60^{\mathrm{a}}$ & $3.28^{\mathrm{a}}$ \\
PC2 & -0.25 & -0.08 & 0.41 & -0.93 & -0.71 & $2.42^{\mathrm{a}}$ & -0.72 & 0.18 & $-6.72^{\mathrm{a}}$ \\
PC3 & -0.20 & -0.83 & 1.06 & -1.45 & -1.55 & -0.78 & 0.29 & -1.21 & $2.91^{\mathrm{a}}$ \\
PC4 & 0.64 & 0.79 & -0.66 & 1.24 & -0.05 & -0.49 & $2.99^{\mathrm{a}}$ & 0.99 & -0.71 \\
PC5 & 0.73 & 0.65 & -0.44 & -0.25 & -0.68 & -0.53 & $-2.56^{\mathrm{a}}$ & 0.29 & 0.14 \\
PC6 & 0.10 & 0.84 & -0.07 & -0.02 & 1.12 & 1.66 & 0.84 & $-2.17^{\mathrm{a}}$ & 0.32 \\
PC7 & -0.78 & 0.09 & 0.49 & -1.06 & 0.51 & -1.03 & 0.04 & 1.34 & -0.19 \\
\hline
\end{tabular}

SWIR2 (1900-2500 nm), which is negatively and $2470 \mathrm{~nm}$ were critical to predict leaf related to leaf water content. However, transpiration using PLSR models. the only waveband within the NIR domain (700-1300 nm) was almost independent of the variation in water content (Knipling 1970, Tucker 1980, Raymond Hunt et al. 1987, Ceccato et al. 2001, Panigrahy et al. 2009).

The importance of the different wavebands selected can be identified from the loading weights on principal components extracted by the PLSR model. High numerical values indicate high importance of the reflected wavelength in the PLSR analysis (Hansen \& Schjoerring 2003 - Tab. 4). Wavebands at 2435, 2445, and $2470 \mathrm{~nm}$ had much higher loading weights on the first PC, with values of $3.68 \times 10^{-4}, 3.60 \times 10^{-4}$, and $3.28 \times 10^{-4}$, respectively. In addition, the wavelength of $2440 \mathrm{~nm}$ showed high loading weights on the fourth and fifth PCs. Therefore, we concluded that the first-order derivative spectra at $2435,2440,2445$,

\section{Superiority of derivative spectra over} original spectra

PLSR analysis based on first-order derivative spectra yielded much more accurate estimations of leaf transpiration. Similarly, more accurate indexes of canopy transpiration could be identified based on derivative spectra in a former study (Jin \& Wang, unpublished). This confirms that the derived spectra can improve the efficiency of transpiration predictions using PLSR models.

As already mentioned, the high accuracy of transpiration estimation based on derivative spectra may be primarily due to a better signal-to-noise ratio, according to Demetriades-Shah et al. (1990) and Yao et al. (2014). It has been reported that chlorophyll-induced changes can be captured in the primary derivatives of the reflectance spectra (Kochubey \& Kazantsev 2007). Fur-

Tab. 5 - Correlation matrix between leaf transpiration (Tr) and the original reflectance of wavelengths involved in the PLSR model.

\begin{tabular}{lccccccccccc}
\hline & \multirow{8}{*}{ Tr } & \multicolumn{10}{c}{ Wavelength $(\mathrm{nm})$} \\
\cline { 3 - 13 } & & $\mathbf{3 7 0}$ & $\mathbf{3 7 5}$ & $\mathbf{4 4 0}$ & $\mathbf{4 6 5}$ & $\mathbf{1 4 0 0}$ & $\mathbf{1 5 4 5}$ & $\mathbf{1 7 9 5}$ & $\mathbf{1 8 0 0}$ & $\mathbf{1 8 6 0}$ & $\mathbf{1 8 8 5}$ \\
\hline $\operatorname{Tr}$ & 1.00 & - & - & - & - & - & - & - & - & - & - \\
$\mathbf{3 7 0}$ & -0.05 & 1.00 & - & - & - & - & - & - & - & - & - \\
$\mathbf{3 7 5}$ & -0.04 & 0.99 & 1.00 & - & - & - & - & - & - & - & - \\
$\mathbf{4 4 0}$ & -0.18 & 0.77 & 0.80 & 1.00 & - & - & - & - & - & - & - \\
$\mathbf{4 6 5}$ & -0.18 & 0.71 & 0.75 & 0.99 & 1.00 & - & - & - & - & - & - \\
$\mathbf{1 4 0 0}$ & -0.06 & 0.53 & 0.57 & 0.90 & 0.92 & 1.00 & - & - & - & - & - \\
$\mathbf{1 5 4 5}$ & -0.02 & 0.51 & 0.55 & 0.88 & 0.90 & 0.99 & 1.00 & - & - & - & - \\
$\mathbf{1 7 9 5}$ & -0.01 & 0.48 & 0.53 & 0.86 & 0.88 & 0.99 & 1.00 & 1.00 & - & - & - \\
$\mathbf{1 8 0 0}$ & -0.01 & 0.48 & 0.53 & 0.86 & 0.88 & 0.99 & 1.00 & 1.00 & 1.00 & - & - \\
$\mathbf{1 8 6 0}$ & -0.04 & 0.50 & 0.54 & 0.87 & 0.90 & 0.99 & 0.99 & 0.99 & 0.99 & 1.00 & - \\
$\mathbf{1 8 8 5}$ & -0.08 & 0.58 & 0.63 & 0.91 & 0.92 & 0.98 & 0.97 & 0.96 & 0.96 & 0.97 & 1.00 \\
\hline
\end{tabular}


Tab. 6 - Correlation matrix between leaf transpiration $(\mathrm{Tr})$ and the first derivative spectra of reflectance of wavelengths involved in the PLSR model.

\begin{tabular}{lrrllllllll}
\hline & \multirow{8}{c}{ Tr } & \multicolumn{10}{c}{ Wavelength $(\mathrm{nm})$} \\
\cline { 3 - 13 } & & $\mathbf{6 7 5}$ & $\mathbf{1 1 9 0}$ & $\mathbf{2 1 8 0}$ & $\mathbf{2 2 7 5}$ & $\mathbf{2 3 5 5}$ & $\mathbf{2 4 3 5}$ & $\mathbf{2 4 4 0}$ & $\mathbf{2 4 4 5}$ & $\mathbf{2 4 7 0}$ \\
\hline $\operatorname{Tr}$ & 1.00 & - & - & - & - & - & - & - & - & - \\
$\mathbf{6 7 5}$ & -0.03 & 1.00 & - & - & - & - & - & - & - & - \\
$\mathbf{1 1 9 0}$ & 0.27 & 0.08 & 1.00 & - & - & - & - & - & - & - \\
$\mathbf{2 1 8 0}$ & 0.07 & -0.19 & -0.70 & 1.00 & - & - & - & - & - & - \\
$\mathbf{2 2 7 5}$ & -0.12 & 0.14 & 0.59 & -0.71 & 1.00 & - & - & - & - & - \\
$\mathbf{2 3 5 5}$ & -0.25 & 0.16 & 0.39 & -0.33 & 0.32 & 1.00 & - & - & - & - \\
$\mathbf{2 4 3 5}$ & 0.49 & -0.12 & 0.34 & -0.16 & 0.13 & 0.22 & 1.00 & - & - & - \\
$\mathbf{2 4 4 0}$ & 0.01 & 0.05 & 0.15 & -0.12 & 0.39 & 0.27 & -0.07 & 1.00 & - & - \\
$\mathbf{2 4 4 5}$ & 0.40 & -0.08 & 0.24 & -0.32 & 0.26 & 0.12 & 0.39 & -0.04 & 1.00 & - \\
$\mathbf{2 4 7 0}$ & 0.13 & 0.00 & -0.03 & -0.05 & 0.15 & 0.09 & -0.14 & 0.08 & 0.14 & 1.00 \\
\hline
\end{tabular}

thermore, increased reflectance of SWIR wavelengths is the most consistent response of leaf reflectance to plant stress, including water stress (Carter 1994, Panigrahy et al. 2009). As the SWIR band is known to provide information on the water content of plants, it has been widely used to assess the water stress of plants (Tucker 1980, Ahlrichs \& Bauer 1983, Raymond Hunt et al. 1987, Baret et al. 1988, Chuvieco et al. 2002).

To further illustrate such relationship, we carried out a correlation analysis of leaf transpiration with each wavelength selected for the PLSR models based on both original reflectance and derivative spectra
(Tab. 5 and Tab. 6, respectively). Selected wavebands from original reflectance data showed much lower correlation coefficients with leaf transpiration than the bands selected from derivative spectra. The highest negative correlation coefficients between transpiration and reflectance only reached -0.18 (wavelengths 440 and 465 $\mathrm{nm})$. On the contrary, the correlation coefficients for derivative spectra bands exceeded 0.4 at two wavelengths of $2435 \mathrm{~nm}$ (0.49) and $2445 \mathrm{~nm}$ (0.40). Furthermore, the pairwise correlations between the selected bands were much higher for the original reflectance data (all above 0.48 , most > 0.8 - Tab. 5). Contrarily, the pairwise
Fig. 6 - Cross-validation results for the first-order derivative spectra with removal of known noise regions for canopy data: the relationships between the numbers of components and the predicted residual sums of squares (PRESS).

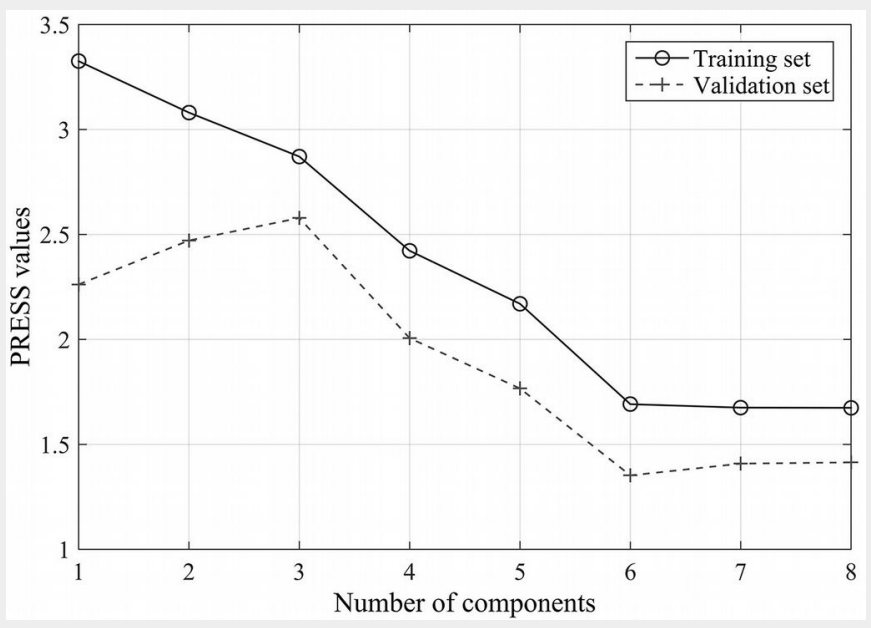

Fig. 7 - The observed versus estimated leaf transpiration va-

lues from the PLSR model based on the first-order derivative spectra with removal of

known noise regions for canopy data.

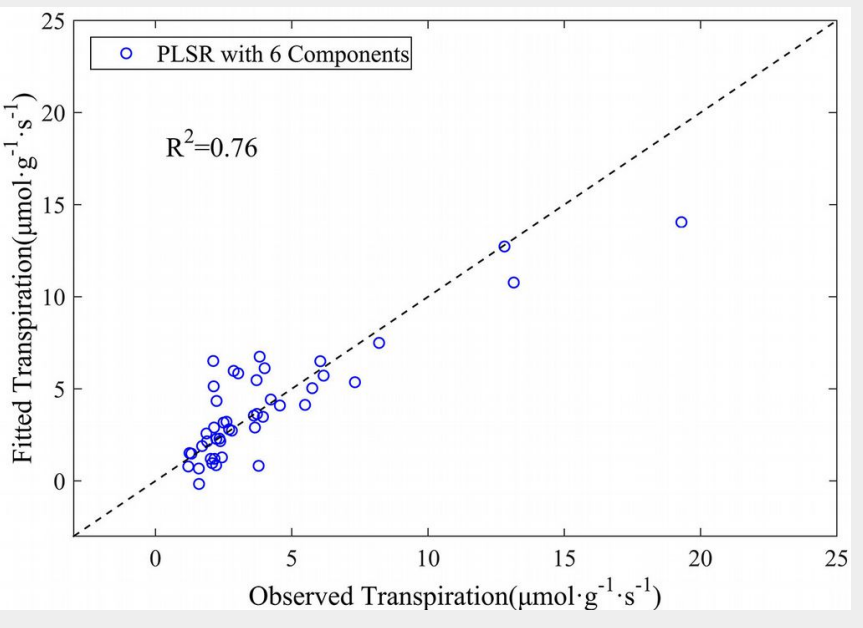

correlation coefficients between the selected wavelengths of the PLSR model based on the derivative spectra had much lower correlations (generally below 0.4 Tab. 6). This confirms that the use of derivative spectra may potentially provide more information when a limited number of wavelengths are included in the PLSR analysis.

\section{Potential large-scale applications with} satellite-borne hyperspectral data

Two important criteria should be taken into account for extending in situ results (such as those obtained in this study) to monitoring transpiration at large scale in the field using satellite-born hyperspectral data. The first is the width of the bands considered, that should be as close as possible to the resolutions of the available hyperspectral sensors; the second is that noise bands should be excluded from the analysis through a suitable selection process. Bandwidths taken at $10 \mathrm{~nm}$ intervals are close to those of some popular hyperspectral sensors currently available, such as Hyperion and AVIRIS (Imanishi et al. 2004), and the spectral regions 350-399, 1355-1420, 1810-1940, and 2470-2500 nm are known as noise regions (Curran 1994, Tian et al. 2001, Kumar et al. 2002, Mutanga et al. 2004, Zhao et al. 2007, Abdel-Rahman et al. 2012) and should therefore be removed from any further analysis.

In this context, an additional PLSR analysis based on the first-order derivative spectra was carried out excluding all the abovementioned noise bands by retaining every tenth wavelength in the spectrum 350$2500 \mathrm{~nm}$. Such procedure finally resulted in 191 out of 2150 wavelengths being involved in the analysis. Eight wavelengths of 1450 , $1960,2000,1070,1980,970,920$, and 2060 $\mathrm{nm}$ were then selected by stepwise regression analysis and included in the PLSR model. Six components were determined through cross-validation analysis (Fig. 6). The coefficient of determination $\left(R^{2}\right)$ was 0.76 , with an RMSE of $1.69 \mu \mathrm{mol} \mathrm{g}^{-1} \mathrm{~s}^{-1}$ (Fig. 7 ), which is comparable to the results obtained using $5 \mathrm{~nm}$ intervals presented above. These findings highlight a promising strategy for developing remote sensing methods to characterize leaf transpiration at a broad scales.

\section{Conclusions}

To verify straightforward statistical relationships between leaf transpiration and reflectance and its derivative spectra, we applied PLSR analysis based on transpiration measures and canopy reflectance spectra (as well as its first derivatives) taken simultaneously. This was carried out on a dominant native plant Haloxylon ammondendron, which is well distributed in the deserts of central Asia. The results demonstrated that the PLSR model based on the first-order derivative spectra of leaf reflectance can trace leaf transpiration with high accuracy, while lower performan- 
ces were obtained when the original reflectance data were considered. Furthermore, the accuracy was also relatively stable for a spectral resolution of $10 \mathrm{~nm}$, which is close to the specification of several hyperspectral sensors such as Hyperion and AVIRIS. This supports the feasibility of directly applying satellite-borne data to trace the dynamics of leaf-scale transpiration. Our results also suggested that first-order derivative spectra at $2435,2440,2445$, and $2470 \mathrm{~nm}$ were critical for the prediction of leaf transpiration by PLSR models. The results obtained in this study should help to lay the basis for developing remote sensing methods aimed at characterizing leaf transpiration at broad scales.

\section{Acknowledgements}

This study was partly supported by the JSPS Grants-in-Aid for Scientific Research (Grant No. 25302001) to Q. Wang. The members of Quantitative Remote Sensing Group of XIEG, CAS are highly acknowledged for their support in field measurements.

\section{References}

Abdel-Rahman EM, Ahmed FB, Ismail R (2012). Random forest regression and spectral band selection for estimating sugarcane leaf nitrogen concentration using EO-1 Hyperion hyperspectral data. International Journal of Remote Sensing 34: 712-728. - doi: 10.1080/01431161.201 2.713142

Abdel-Rahman EM, Mutanga O, Odindi J, Adam E, Odindo A, Ismail R (2014). A comparison of partial least squares (PLS) and sparse PLS regressions for predicting yield of Swiss chard grown under different irrigation water sources using hyperspectral data. Computers and Electronics in Agriculture 106: 11-19. - doi: 10.1016/ j.compag.2014.05.001

Ahlrichs JS, Bauer ME (1983). Relation of agronomic and multispectral reflectance characteristics of spring wheat canopies. Agronomy Journal 75: 987-993. - doi: 10.2134/agronj1983.0 0021962007500060029x

Ansley R, Jacoby P, Hicks R (1991). Leaf and whole plant transpiration in honey mesquite following severing of lateral roots. Journal of Range Management 44 (6): 577. - doi: 10.2307/4003 039

Baret F, Guyot G, Begue A, Maurel P, Podaire A (1988). Complementarity of middle-infrared with visible and near-infrared reflectance for monitoring wheat canopies. Remote Sensing of Environment 26: 213-225. - doi: 10.1016/00344257(88)90078-8

Carter GA (1994). Ratios of leaf reflectance in narrow wavebands as indicators of plant stress. International Journal of Remote Sensing 15: 697-703. - doi: 10.1080/01431169408954109

Ceccato P, Flasse S, Tarantola S, Jacquemoud S, Grégoire JM (2001). Detecting vegetation leaf water content using reflectance in the optical domain. Remote Sensing of Environment 77: 22-33. - doi: 10.1016/S0034-4257(01)00191-2

Chappelle EW, Kim MS, McMurtrey JE (1992). Ratio analysis of reflectance spectra (RARS): an algorithm for the remote estimation of the concentrations of chlorophyll a, chlorophyll b, and carotenoids in soybean leaves. Remote Sensing of Environment 39: 239-247. - doi: 10.1016/0034-4257(92)90089-3

Chen S, Hong X, Harris CJ, Sharkey PM (2004). Sparse modeling using orthogonal forward regression with PRESS statistic and regularization. IEEE Transactions on Systems, Man, and Cybernetic, Part B: Cybernetics 34: 898-911. doi: 10.1109/TSMCB.2003.817107

Cho MA, Skidmore A, Corsi F, Van Wieren SE, Sobhan I (2007). Estimation of green grass/ herb biomass from airborne hyperspectral imagery using spectral indices and partial least squares regression. International Journal of Applied Earth Observation and Geoinformation 9: 414-424. - doi: 10.1016/j.jag.2007.02.001

Chuvieco E, Riaño D, Aguado I, Cocero D (2002). Estimation of fuel moisture content from multitemporal analysis of Landsat Thematic Mapper reflectance data: applications in fire danger assessment. International Journal of Remote Sensing 23: 2145-2162. - doi: 10.1080/01431160110 069818

Curran P (1994). Imaging spectrometry - its present and future role in environmental researc. In: "Imaging Spectrometry - a Tool for Environmental Observations" (Hill J, Mégier J eds). Springer, The Netherlands, pp. 1-23. [online] URL: http://ppg.sagepub.com/content/ 18/2/247.short

Dauzat J, Rapidel B, Berger A (2001). Simulation of leaf transpiration and sap flow in virtual plants: model description and application to a coffee plantation in Costa Rica. Agricultural and Forest Meteorology 109: 143-160. - doi: 10.1016/ S0168-1923(01)00236-2

Demetriades-Shah TH, Steven MD, Clark JA (1990). High resolution derivative spectra in remote sensing. Remote Sensing of Environment 33: 55-64. - doi: 10.1016/0034-4257(90)90055-Q Dorigo WA, Zurita-Milla R, De Wit AJW, Brazile J, Singh R, Schaepman ME (2007). A review on reflective remote sensing and data assimilation techniques for enhanced agroecosystem modeling. International Journal of Applied Earth Observation and Geoinformation 9: 165-193. doi: 10.1016/j.jag.2006.05.003

Doughty CE, Asner GP, Martin RE (2011). Predicting tropical plant physiology from leaf and canopy spectroscopy. Oecologia 165: 289-299. doi: 10.1007/s00442-010-1800-4

Fu Y, Yang G, Wang J, Song X, Feng H (2014). Winter wheat biomass estimation based on spectral indices, band depth analysis and partial least squares regression using hyperspectral measurements. Computers and Electronics in Agriculture 100: 51-59. - doi: 10.1016/j.com pag.2013.10.010

Hansen PM, Schjoerring JK (2003). Reflectance measurement of canopy biomass and nitrogen status in wheat crops using normalized difference vegetation indices and partial least squares regression. Remote Sensing of Environment 86: 542-553. - doi: 10.1016/S0034-4257(03) 00131-7

He D, Liu Y, Pan Z, An P, Wang L, Dong Z, Zhang J, Pan X, Zhao P (2013). Climate change and its effect on reference crop evapotranspiration in central and western Inner Mongolia during 1961-2009. Frontiers of Earth Science 7: 417-428.
- doi: 10.1007/s11707-013-0381-z

Huang Z, Turner BJ, Dury SJ, Wallis IR, Foley WJ (2004). Estimating foliage nitrogen concentration from HYMAP data using continuum removal analysis. Remote Sensing of Environment 93: 18-29. - doi: 10.1016/j.rse.2004.06.008 Hunsmann S, Wunderle K, Wagner S, Rascher U, Schurr U, Ebert V (2008). Absolute, high resolution water transpiration rate measurements on single plant leaves via tunable diode laser absorption spectroscopy (TDLAS) at $1.37 \mu \mathrm{m}$. Applied Physics B 92: 393-401. - doi: 10.1007/s0034 0-008-3095-2

Imanishi J, Sugimoto K, Morimoto $Y$ (2004). Detecting drought status and LAI of two Quercus species canopies using derivative spectra. Computers and Electronics in Agriculture 43: 109-129. - doi: 10.1016/j.compag.2003.12.001

Inoue Y, Sakaiya E, Zhu Y, Takahashi W (2012). Diagnostic mapping of canopy nitrogen content in rice based on hyperspectral measurements. Remote Sensing of Environment 126: 210-221. - doi: 10.1016/j.rse.2012.08.026

Jarvis P, Catsky J (1971). Chamber microclimate and principles of assimilation chamber design. In: "Plant Photosynthetic Production. Manual of Methods". Dr. W. Junk N.V. Publishers, The Hague, The Netherlands, pp. 59-77.

Jennrich RI (1977). Stepwise regression. In: "Statistical methods for digital computers" (Enslein K, Ralston A, Wilf HS eds). Wiley, New York, USA, pp. 58-75.

Knipling EB (1970). Physical and physiological basis for the reflectance of visible and nearinfrared radiation from vegetation. Remote Sensing of Environment 1: 155-159. - doi: 10.1016/ So034-4257(70)80021-9

Kochubey SM, Kazantsev TA (2007). Changes in the first derivatives of leaf reflectance spectra of various plants induced by variations of chlorophyll content. Journal of Plant Physiology 164: 1648-1655. - doi: 10.1016/j.jplph.2006. 11.007

Kumar L, Schmidt K, Dury S, Skidmore A (2002). Imaging spectrometry and vegetation science. In: "Imaging Spectrometry". Springer Science+Business Media BV, The Netherlands, pp. 111-155. - doi: 10.1007/978-0-306-47578-8

Li P, Wang Q (2012). Retrieval of chlorophyll for assimilating branches of a typical desert plant through inversed radiative transfer models. International Journal of Remote Sensing 34: 2402-2416. - doi: 10.1080/01431161.2012.744859

Li Z, Li R (1981). Anatomical observation of assimilating branches of nine xerophytes in Gansu. Acta Botanica Sinica 23: 181-185. [online] URL: http://kbd.kew.org//kbd/detailedresult.do?id=60 989

Marino G, Pallozzi E, Cocozza C, Tognetti R, Giovannelli A, Cantini C, Centritto M (2014). Assessing gas exchange, sap flow and water relations using tree canopy spectral reflectance indices in irrigated and rainfed Olea europaea L. Environmental and Experimental Botany 99: 43-52. doi: 10.1016/j.envexpbot.2013.10.008

McDowell NG, White S, Pockman WT (2008). Transpiration and stomatal conductance across a steep climate gradient in the southern Rocky Mountains. Ecohydrology 1: 193-204. - doi: 10.10 $02 / e c 0.20$

Monteith J (1965). Evaporation and environ- 
ment. Symposia of the Society for Experimental Biology 19: 205-224. [online] URL: http://www.unc.edu/courses/2007fall/geog/801 1001/www/ET/Monteith65.pdf

Mutanga O, Skidmore AK, Prins HHT (2004). Predicting in situ pasture quality in the Kruger National Park, South Africa, using continuumremoved absorption features. Remote Sensing of Environment 89: 393-408. - doi: 10.1016/j. rse.2003.11.001

Naithani KJ, Ewers BE, Pendall E (2012). Sap fluxscaled transpiration and stomatal conductance response to soil and atmospheric drought in a semi-arid sagebrush ecosystem. Journal of Hydrology 464-465: 176-185. - doi: 10.1016/j.jhy drol.2012.07.008

Nguyen HT, Lee BW (2006). Assessment of rice leaf growth and nitrogen status by hyperspectral canopy reflectance and partial least square regression. European Journal of Agronomy 24: 349-356. - doi: 10.1016/j.eja.2006.01.001

Osborne SD, Künnemeyer R, Jordan RB (1997). Method of wavelength selection for partial least squares. Analyst 122: 1531-1537. - doi: 10.10 39/a703235h

Panigrahy RK, Ray S, Panigrahy S (2009). Study on the utility of IRS-P6 AWIFS SWIR band for crop discrimination and classification. Journal of Indian Society of Remote Sensing 37: 325333. - doi: 10.1007/s12524-009-0026-6

Pearcy R, Schulze ED, Zimmermann R (1989). Measurement of transpiration and leaf conductance. In: "Plant Physiological Ecology" (Pearcy $\mathrm{R}$, Ehleringer $\mathrm{J}$, Mooney $\mathrm{H}$, Rundel $\mathrm{P}$ eds). Springer, The Netherlands, pp. 137-160. - doi: 10.1007/978-94-009-2221-1_8

Peñuelas J, Filella I (1998). Visible and nearinfrared reflectance techniques for diagnosing plant physiological status. Trends in Plant Science 3: 151-156. - doi: 10.1016/S1360-1385(98) 01213-8

Rady AM, Guyer DE, Kirk W, Donis-González IR (2014). The potential use of visible/near infrared spectroscopy and hyperspectral imaging to predict processing-related constituents of po- tatoes. Journal of Food Engineering 135: 11-25. doi: 10.1016/j.jfoodeng.2014.02.021

Ramoelo A, Skidmore AK, Cho MA, Mathieu R, Heitkönig IMA, Dudeni-Tlhone N, Schlerf $M$, Prins HHT (2013). Non-linear partial least square regression increases the estimation accuracy of grass nitrogen and phosphorus using in situ hyperspectral and environmental data. ISPRS Journal of Photogrammetry and Remote Sensing 82: 27-40. - doi: 10.1016/j.isprsjprs.2013.04.0 12

Raupach M, Finnigan J (1988). Single-layer models of evaporation from plant canopies are incorrect but useful, whereas multilayer models are correct but useless: discussion. Functional Plant Biology 15: 705-716. [online] URL: http://www.publish.csiro.au/paper/PP9880705. htm

Raymond Hunt E, Rock BN, Nobel PS (1987). Measurement of leaf relative water content by infrared reflectance. Remote Sensing of Environment 22 (3): 429-435. - doi: 10.1016/00344257(87)90094-0

Ryu C, Suguri M, Umeda M (2009). Model for predicting the nitrogen content of rice at panicle initiation stage using data from airborne hyperspectral remote sensing. Biosystems Engineering 104: 465-475. - doi: 10.1016/j.biosys temseng.2009.09.002

Ryu C, Suguri M, Umeda M (2011). Multivariate analysis of nitrogen content for rice at the heading stage using reflectance of airborne hyperspectral remote sensing. Field Crops Research 122: 214-224. - doi: 10.1016/j.fcr.2011.03.0 13

Serbin SP, Dillaway DN, Kruger EL, Townsend PA (2012). Leaf optical properties reflect variation in photosynthetic metabolism and its sensitivity to temperature. Journal of Experimental Botany 63: 489-502. - doi: 10.1093/jxb/err294 Shao J (1993). Linear model selection by crossvalidation. Journal of the American Statistical Association 88: 486-494. - doi: 10.1080/0162145 9.1993.10476299

Smith W, Geller G (1980). Leaf and environmen- tal parameters influencing transpiration: theory and field measurements. Oecologia 46: 308313. - doi: $10.1007 / B F 00346257$

Tian Q, Tong Q, Pu R, Guo X, Zhao C (2001). Spectroscopic determination of wheat water status using 1650-1850 nm spectral absorption features. International Journal of Remote Sensing 22: 2329-2338. - doi: 10.1080/01431160118199 Tucker CJ (1980). Remote sensing of leaf water content in the near infrared. Remote Sensing of Environment 10: 23-32. - doi: 10.1016/00344257(80)90096-6

Wold S, Sjöström M, Eriksson L (2001). PLS-regression: a basic tool of chemometrics. Chemometrics and Intelligent Laboratory Systems 58: 109-130. - doi: 10.1016/S0169-7439(01)00155-1 Yao X, Ren H, Cao Z, Tian Y, Cao W, Zhu Y, Cheng $T$ (2014). Detecting leaf nitrogen content in wheat with canopy hyperspectrum under different soil backgrounds. International Journal of Applied Earth Observations and Geoinformation 32: 114-124. - doi: 10.1016/j.jag.2014.03.014 Yi Q, Jiapaer G, Chen J, Bao A, Wang F (2014). Different units of measurement of carotenoids estimation in cotton using hyperspectral indices and partial least square regression. ISPRS Journal of Photogrammetry and Remote Sensing 91: 72-84. - doi: 10.1016/j.isprsjprs.2014.01.004 Zhang X, Liu F, He Y, Gong X (2013). Detecting macronutrients content and distribution in oilseed rape leaves based on hyperspectral imaging. Biosystems Engineering 115: 56-65. - doi: 10.1016/j.biosystemseng.2013.02.007

Zhao D, Reddy KR, Kakani VG, Read JJ, Koti S (2007). Canopy reflectance in cotton for growth assessment and lint yield prediction. European Journal of Agronomy 26: 335-344. doi: 10.1016/j.eja.2006.12.001

Zheng C, Wang Q (2014). Spatiotemporal variations of reference evapotranspiration in recent five decades in the arid land of Northwestern China. Hydrological Processes 28 (25): 61246134. - doi: 10.1002/hyp.10109 